Article

\title{
Application of Breathing Architectural Members to the Natural Ventilation of a Passive Solar House
}

\author{
Kyung-Soon Park ${ }^{1}$, Sang-Woo Kim ${ }^{2}$ and Seong-Hwan Yoon ${ }^{2, *}$ \\ 1 Department of Building Systems Engineering, Dong-Eui University, Busan 47340, Korea; pks2180@deu.ac.kr \\ 2 Department of Architecture, Pusan National University, Busan 46241, Korea; wooya930@nate.com \\ * Correspondence: yoon@pusan.ac.kr; Tel.: +82-51-510-2355
}

Academic Editor: Jihong Wang

Received: 5 November 2015; Accepted: 8 March 2016; Published: 17 March 2016

\begin{abstract}
The efficient operation of a passive solar house requires an efficient ventilation system to prevent the loss of energy and provide the required ventilation rates. This paper proposes the use of "breathing architectural members" (BAMs) as passive natural ventilation devices to achieve much improved ventilation and insulation performance compared to mechanical ventilation. Considering the importance of evaluating the ventilation and insulation performances of the members, we also propose numerical models for predicting the heat and air movements afforded by the members. The numerical model was validated by comparison with experimental results. The effectiveness of the BAMs was also verified by installation in houses located in an area with warm climate. For this purpose, chamber experiments were performed using samples of the BAMs, as well as numerical simulations to assess natural ventilation and heat load. The main findings of the study are as follows: (1) the one-dimensional chamber experiments confirmed the validity of the numerical models for predicting the heat and air movements afforded by the BAMs. Comparison of the experimental and calculated values for the temperature of air that flowed into the room from outside revealed a difference of less than 5\%; (2) observations of the case studies in which BAMs were installed in the ceilings and exterior walls of Tokyo model houses revealed good annual ventilation and energy-saving effects. When BAMs with an opening area per unit area of $A=0.002 \mathrm{~m}^{2} / \mathrm{m}^{2}$ were applied to three surfaces, the required ventilation rate was $0.5 \mathrm{ACH}$ (air changes per hour), and this was achieved consistently. Compared to a house with general insulation and conventional mechanical ventilation, heating load was reduced by $15.3 \%-40.2 \%$ depending on the BAM installation points and the differing areas of the house models.
\end{abstract}

Keywords: passive; natural ventilation; heat load; full-size experiment

\section{Introduction}

With the increasing demand for passive (energy efficient) houses in moderate-climate countries such as Korea and Japan, more airtight and heat-insulated houses are being developed. In such houses, mechanical ventilation by means of fans and natural ventilation through openings are used to maintain good indoor air quality. However, deterioration of the air and loss of energy occur as a result of increased ventilation load when the ventilation fans are turned off or ventilation channels are not appropriately opened. As an efficient means of solving this problem, passive ventilation involving continuous natural ventilation through the skins of a building has been proposed.

However, for the efficient operation of a solar house, it is important not only to improve the efficiency of energy generation, but also to prevent the loss of energy. Accordingly, a ventilation device is required that satisfies the required ventilation of the solar house while exhibiting no heat loss. It is considered that the use of a passive natural ventilation system and surface-treated exterior walls in a solar house is far more efficient than the adoption of point-to-point mechanical ventilation. 
Such a design not only continuously affords the required minimum ventilation rate, but can also better deal with an increase in the ventilation load, which would otherwise degrade the indoor thermal environment. Along this line, Hoyano et al. [1] proposed the use of "breathing architectural members" (BAMs) with natural ventilation functions as a surface treatment for the exterior walls and ceilings of a passive solar house in warm-climate areas such as Tokyo. This also enables control of the flow of heat, air, and moisture.

A BAM includes internal and external materials with ventilation resistances lower than that of the core part, which consists of a multi-layered air body made from porous aluminium sheets, as shown in Figure 1. The member allows air to flow between the indoor and outdoor sides through its entire surface under the effect of the differing indoor and outdoor temperatures or external wind pressure. This ensures that the required ventilation performance is maintained. In addition, the vapour that flows through the BAM is rapidly discharged by air movement, thereby avoiding damage resulting from internal condensation. Although some studies have been conducted on ventilation through building skins, such as those of Dimoudi et al. [2], Imbabi et al. [3], and Stavridou et al. [4], Biserni et al. [5], the present study was unique in that the employed BAM did not require the driving force of a mechanical fan, but only natural wind pressure and temperature difference. Based on analysis of meteorological data, internal condensation during the period that the air flowed through the member was prevented by the use of porous aluminium sheets with different opening ratios. The efficiency of the heat exchange inside the member was also maximized by using multiple layers of the aluminium sheets.

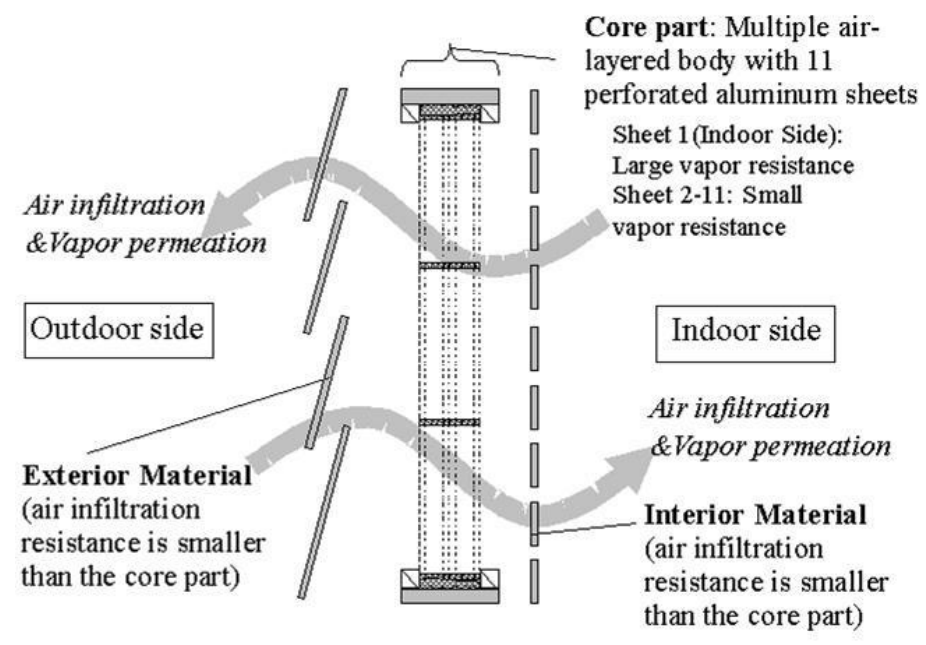

Figure 1. Basic structure of a BAM.

Hoyano et al. [1,6] proposed the use of a one-dimensional prediction method to adapt a BAM to a warm-climate area with regard to the movement of air, heat, and water vapour. Yoon et al. [7] performed experiments under weather conditions representative of a warm-climate area. The results were used to verify achievement of the target ventilation performances, insulation, and water vapour movement. It was found that, when a BAM was applied to a passive solar house, it could be considered as a passive architectural member under stable conditions. However, this is limited to the case of using a single member, and the evaluation of ventilation performance and energy-saving effect of a BAM in a real full-scale house was left to further study.

In the present study, we comprehensively evaluated the performance of BAMs when applied to the ceiling and outer walls of a passive house. BAM samples were fabricated for use in one-dimensional chamber experiments. Numerical models for evaluating the removed heat and air movement were developed and verified by comparing their predictions with experimental results. The effectiveness of the BAMs was confirmed by numerical simulation using the air and heat movement prediction 
method and the ventilation calculation method. The present study was a follow-up to that of Yoon and Hoyano [7]; however, despite their methodological similarities, the present chamber experiment employed a BAM unit with a casing specifically designed for application to an actual house. In addition, the variation in ventilation depended on the direction of the air flow, which was determined by pressurizing and depressurizing the unit.

\section{Numerical Prediction Models for Quantifying Heat and Air Movement}

The calculation range of the numerical models for predicting the amounts of heat and air movement by the BAM was set between the indoor-side air layer of the first aluminium sheet and the outdoor-side air layer of the $m$ th aluminium sheet. The boundary conditions were defined by the indoor and outdoor temperatures, the air infiltration direction, and the differential pressure across the member. The calculations were performed in such a way as to simultaneously validate the different components of the heat and air movements like Figure 2, by taking the following items into consideration based on the findings of a previous study [1]:

- Convective heat transfer by a porous aluminium sheet and its air layer, $E_{c}$

- Radiant heat transfer through adjacent perforated aluminium sheets, $E_{r}$

- Air infiltration due to differing air pressure across the hole, between two air layers and the movement of heat due to the air infiltration, $E_{i}$

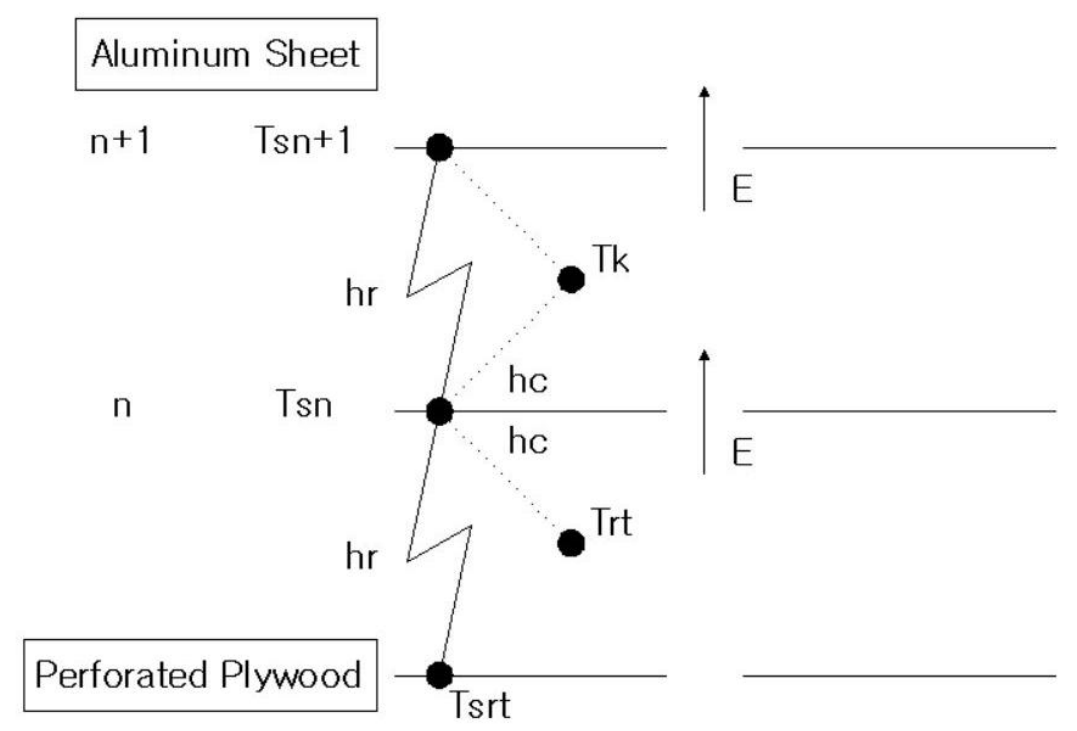

Figure 2. Schematic of the heat transfer numerical model.

The thickness of the aluminium films used to fabricate the core part of the BAM was $25 \mu \mathrm{m}$ and heat transfer by thermal conduction through the aluminum films could be ignored in the heat calculation for the core part, which also contained air layers.

When predicting the volume of air infiltration, it was assumed that the buoyancy due to the temperature difference across the air layer could be ignored, but not the pressure difference between the indoor and outdoor sides of the wall. The volume of air infiltration, $V\left[\mathrm{~m}^{3} /\left(\mathrm{m}^{2} \mathrm{~s}\right)\right]$, through the wall is given by:

$$
V=c A\left(\frac{4}{\gamma_{r}+\gamma_{o}}(P)\right)^{1 / 2}
$$

where:

$$
\frac{1}{(c A)^{2}}=\sum_{n=1}^{m} \frac{1}{\left(c_{n} A_{n}\right)^{2}}
$$


where:

c: Flow coefficient [-] [8]

A: Opening area per unit area $\left[\mathrm{m}^{2} / \mathrm{m}^{2}\right]$

$\gamma: \operatorname{Air} \operatorname{density}\left(=1.293 \times 273.15 / \mathrm{T}[\mathrm{K}]\left[\mathrm{kg} / \mathrm{m}^{3}\right)\right.$

$P$ : Air pressure $[\mathrm{Pa}]$

r: Indoor

o: Outdoor

$m$ : Number of aluminium films

Heat movement is quantified as follows:

(1) The convective heat transfer rate from the surface of an aluminium sheet, $h_{c}\left[\mathrm{~W} / \mathrm{m}^{2 \circ} \mathrm{C}\right]$, is determined using the following equations of the Nusselt number $N u$ and by convective heat transfer (The Nusselt number was determined with reference to [9]. The convective heat transfers of fully developed laminar flows through pipes with different cross sections are defined in this work, and $\mathrm{Nu}=7.54$ was adopted as the appropriate value for the present study).

$$
\begin{gathered}
N_{u}=h_{c} d / \lambda=7.54 \\
h_{c}=3.77 \lambda D(\text { where }, \quad d=4 D / 2=2 D) \\
\text { therefore } E_{c}=\quad h_{c}\left(T s_{n}-T_{k}\right)
\end{gathered}
$$

(2) The radiant heat transfer rate, $h_{r}\left[\mathrm{~W} / \mathrm{m}^{2 \circ} \mathrm{C}\right]$, between the surfaces of adjacent aluminium sheets is determined by the following equation :

$$
h_{r n, n+1}=\varepsilon_{n, n+1} \sigma\left[\left(T s_{n}+273.15\right)+\left(T s_{n+1}+273.15\right)\right] \times\left[\left(T s_{n}+273.15\right)^{2}+\left(T s_{n}+273.15\right)^{2}\right]
$$

However:

$$
\begin{aligned}
& 1 / \varepsilon_{n n+1}=\left(1 / \varepsilon_{n}\right)+\left(1 / \varepsilon_{n+1}\right)-1 \\
& \text { therefore } E_{r}=h_{r}\left(T s_{n+1}-T s_{n}\right)
\end{aligned}
$$

(3) The heat movement, $E_{i}\left[\mathrm{~W} / \mathrm{m}^{2}\right]$, that accompanies the air infiltration can be determined using the following equation (The formula used to calculate the heat transfer accompanying air permeance $\mathrm{E}\left[\mathrm{W} / \mathrm{m}^{2 \circ} \mathrm{C}\right]$ is similar to the method for determining ventilation load presented in [10]):

$$
E_{i n n+1}=V C_{p} \gamma\left(T_{k}-T_{k+1}\right)
$$

where:

$\mathrm{Nu}$ : Nusselt number

$d$ : Equivalent diameter of pipe section [m]

$\lambda$ : Thermal conductivity of air $[\mathrm{W} /(\mathrm{mK})]$

$D$ : Thickness of air layer $[\mathrm{m}]$

$\varepsilon_{n}$ : Emissivity of aluminium sheet, $\mathrm{n}[-]$

$T s_{n}$ : Surface temperature of aluminium sheet, $\mathrm{n}\left[{ }^{\circ} \mathrm{C}\right]$

$\sigma$ : Stefan-Boltzmann constant $\left(=5.67 \times 10^{-8}\right)\left[\mathrm{W} /\left(\mathrm{m}^{2} \mathrm{~K}\right)\right]$

$C_{p}$ : Specific heat at constant pressure $\left[\mathrm{J} /\left(\mathrm{kg}^{\circ} \mathrm{C}\right)\right]$

$\mathrm{T}_{k}$ : Temperature of air layer, $\mathrm{k}\left[{ }^{\circ} \mathrm{C}\right]$ 


\section{Heat and Air Infiltration Experiment}

\subsection{Outline of the Experiment}

The core part of each BAM sample consisted of 11 porous aluminium sheets, each of which had a low emissivity of 0.1 or less on both sides, and $0.005 \mathrm{~m}$ air layers on the core material, which was woven to $0.15 \times 0.15 \mathrm{~m}$ (see Figure 3 ). The average hole diameter and hole spacing of the porous aluminium sheets were set to 0.00145 and $0.028 \mathrm{~m}$, respectively, for sheet No. 1 from the indoor side, and 0.00026 and $0.0011 \mathrm{~m}$ for sheets $2-11$. This was based on the usual values used for BAMs under normal conditions in a warm-climate [1].

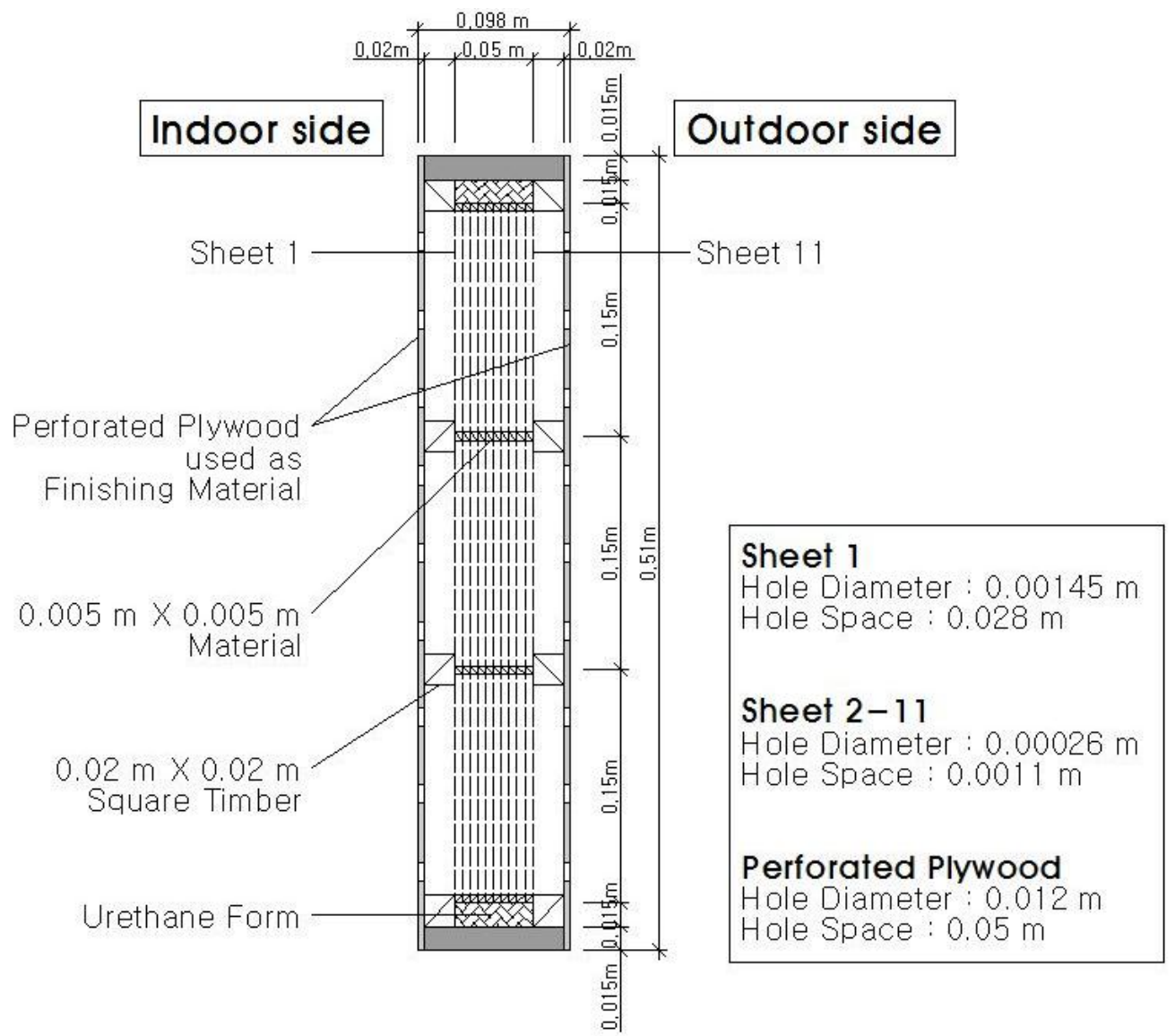

Figure 3. BAM test sample.

The BAM samples were made from polyethylene plywood sheets, which were installed in the experimental house as finishing materials. A space of $0.015 \mathrm{~m}$ was left between the mould of the wooden case and the BAM, and was filled with water-blown urethane foam so that the flow through the member could be considered a one-dimensional laminar flow.

With regard to the specifications of the porous polyethylene plywood used as the finishing material, the hole diameter was set to $0.012 \mathrm{~m}$, the hole spacing to $0.05 \mathrm{~m}$, and the opening rate to $4.5 \%$. Generally, the finished structure of a BAM affects the air permeability of the member, and hence the thermal insulation and vapour permeation. In the samples employed in the present study, however, the finishing materials had an extremely low air permeance resistance compared to the core part, and therefore did not affect the overall air permeance and heat insulation performance of the members. Hence, in the following discussion of the air permeance and heat insulation performance of the members, sheets numbered 1 to 11 are considered to determine the air infiltration and thermal 
insulation performances of the BAM. The temperature of the air in the $0.02 \mathrm{~m}$ air layer formed on the indoor side is also regarded as the actual temperature of the air flowing inwards.

Figure 4 shows the experimental setup, which was conducted in an artificial climate test room in which the relative temperature of outdoor air was automatically maintained within $\pm 1{ }^{\circ} \mathrm{C}$ of the target value. Conversely, the relative temperature of the indoor air was manually controlled by means of an electric heating sheet and a portable electric fan, which provided a sufficient volume of mixed air. The BAM $(0.445 \times 0.45 \times 0.09 \mathrm{~m})$ was covered with polystyrene boards to make it airtight and achieve excellent insulation, after which it was installed in the chamber. The internal structure of the BAM between the $0.004 \mathrm{~m}$-thick porous polystyrene panels (hole diameter $=0.012 \mathrm{~m}$, hole spacing $=0.05 \mathrm{~m}$ ) on the indoor and outdoor sides consisted of 11 layers, which included porous PET-AL sheets and a layer of wooden grids spaced at $0.005 \mathrm{~m}$. The sheets on either side of the grid were covered with waterproof paint and sandwiched between PET-AL sheets. In addition, a polystyrene panel with $0.015 \mathrm{~m}$ air layer was placed on either side of the BAM.

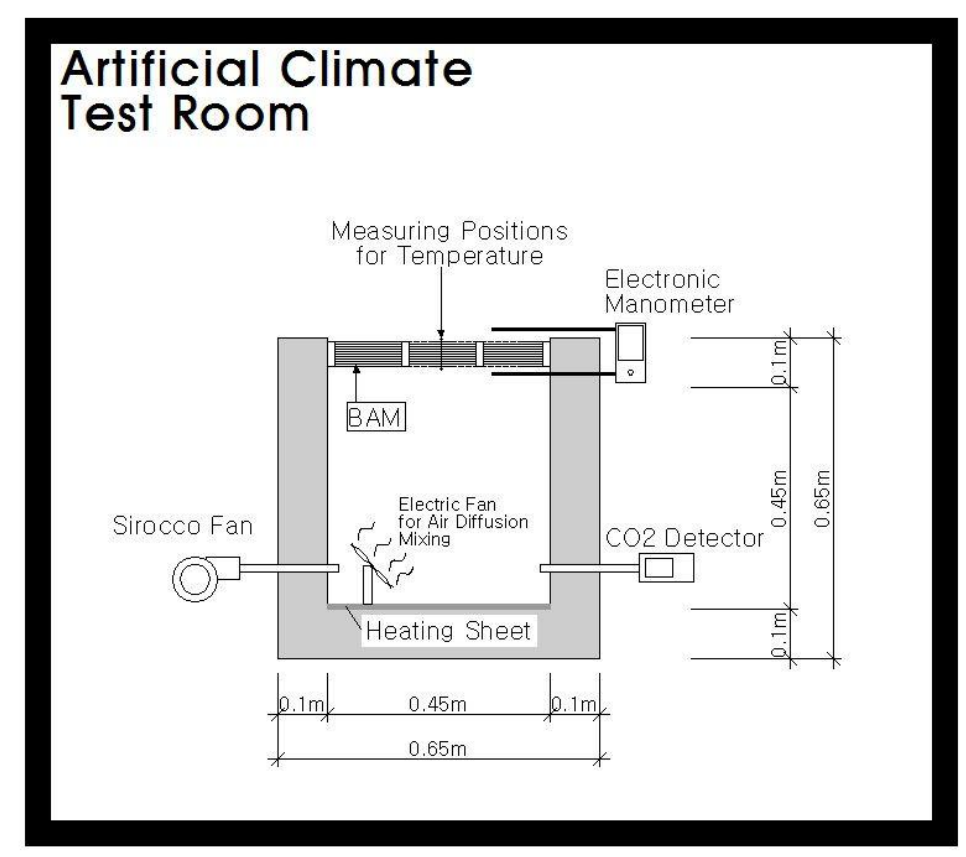

Figure 4. Experimental setup for simulating the effects of wind variation [5].

In the experiment, a T-type thermocouple was used for temperature measurement. A differential pressure gauge (TESTO 512, Testo, Lenzkirch, Germany) and multi-gas analyser (RAE System, MultiRAE IR, San Jose, CA, USA) were also employed. The performance and specifications of the measuring instruments were as presented in Tables 1 and 2.

Table 1. Performance and specifications of the differential pressure gauge.

\begin{tabular}{|c|c|c|}
\hline Classification & Pressure Cell & Pitot Tube \\
\hline Measurement Range & $-200-200 \mathrm{~Pa}$ & $0-17.5 \mathrm{~m} / \mathrm{s}$ \\
\hline Resolution & $0.1 \mathrm{~Pa}$ & $0.1 \mathrm{~m} / \mathrm{s}$ \\
\hline Error Rate & \multicolumn{2}{|c|}{$0.5 \%$} \\
\hline
\end{tabular}

Table 2. Performance and specifications of the multi-gas analyser.

\begin{tabular}{|c|c|}
\hline Item & Value \\
\hline Measurement Item $\quad \mathrm{CO}_{2}$ & 0-50,000 ppm (Resolution: 10 ppm) \\
\hline Operating Temperature & $-20-45^{\circ} \mathrm{C}$ \\
\hline
\end{tabular}




\subsection{Experimental Conditions and Methodology}

The outdoor air temperature was set to $5^{\circ} \mathrm{C}$, based on outdoor night-time temperature in the Tokyo area during winter. The temperature of the air inside the house was set to $25^{\circ} \mathrm{C}$ by floor heating under normal conditions. If a passive solar house is operated under these conditions, there would be significant fluctuation of room temperature. In the present study, however, only the wind pressure was considered a variable, while room temperature was considered constant.

To apply a constant air pressure to the ceiling, the external air pressure was reproduced by blowing the air (pressurization) and allowing it to expel (decompression) through the blower that formed part of the experimental setup. To evaluate the effect of external air pressure, room temperature was regulated by the floor heating. The conditions were coordinated to allow air to flow into the room, the temperature of which was set to $25^{\circ} \mathrm{C}$, with the heat source controlled to $134 \mathrm{~W} / \mathrm{m}^{2}$ (floor surface temperature $=26.5^{\circ} \mathrm{C}$ ) under normal conditions.

The volume of air infiltration under constant air pressure was determined experimentally by means of the tracer method using carbon dioxide $\left(\mathrm{CO}_{2}\right)$ traced gas. The pressure applied to the sample was gradually varied within $0-10$ Pa by means of a pressurization and decompression device.

The main measurement items were the following of air infiltration and the temperature distribution within the member. The measurement parts and items are as shown in Figure 5.

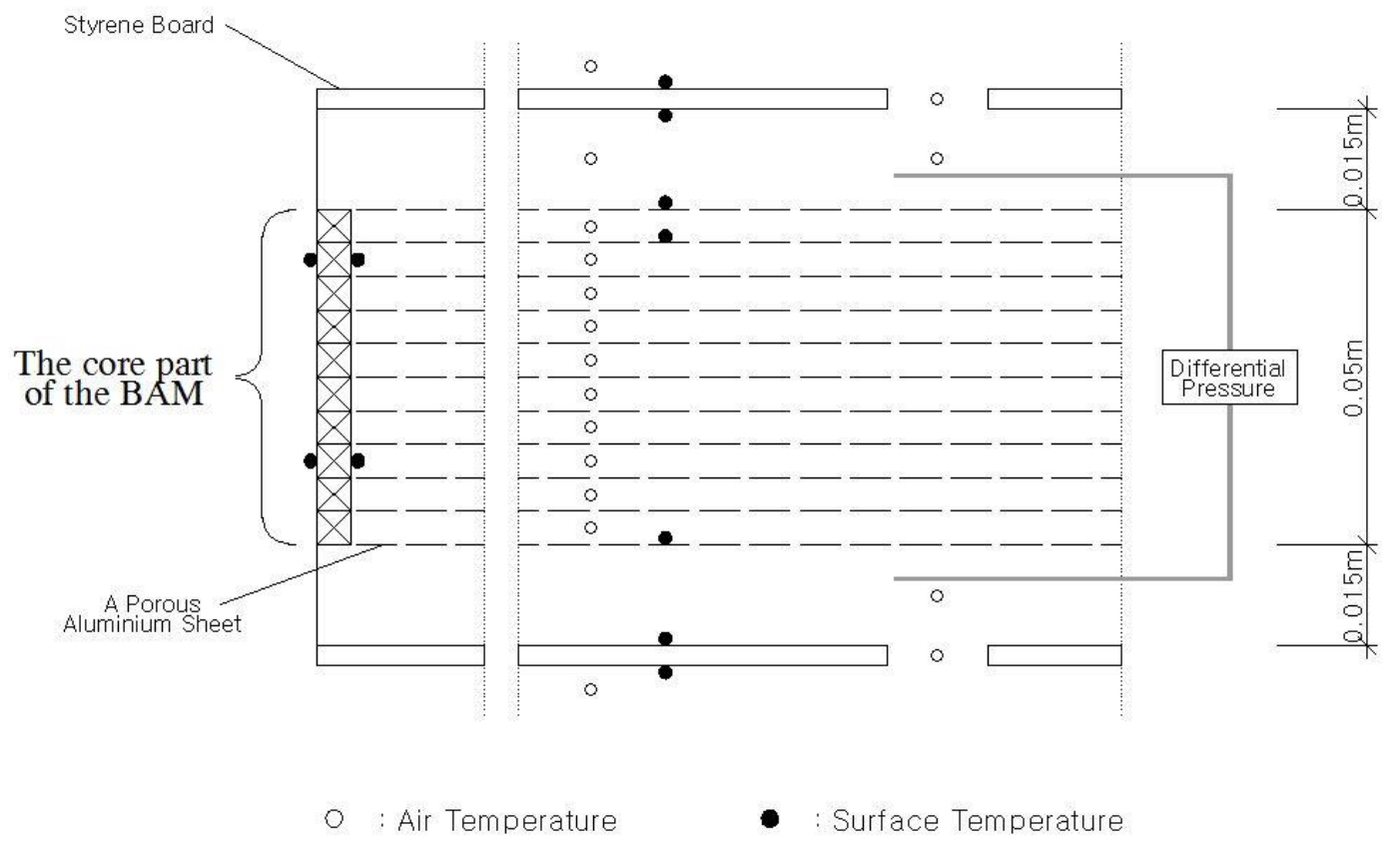

Figure 5. Measurement parts and items.

\subsection{Experimental Results}

\subsubsection{Air Infiltration Characteristics under Constant Pressurization}

Figure 6 compares the measured and calculated (Equation (1)) volumes of air infiltration.

The modeled and experimental results are in better agreement up to $5 \mathrm{~Pa}$ under decompression conditions, while the deviations range between $0.4 \%$ and $33.5 \%$ at more than 3 Pa during pressurization. This observation can be attributed to the variation of the shape loss resistance of the sheet holes with the perforation direction of the aluminium sheet. 


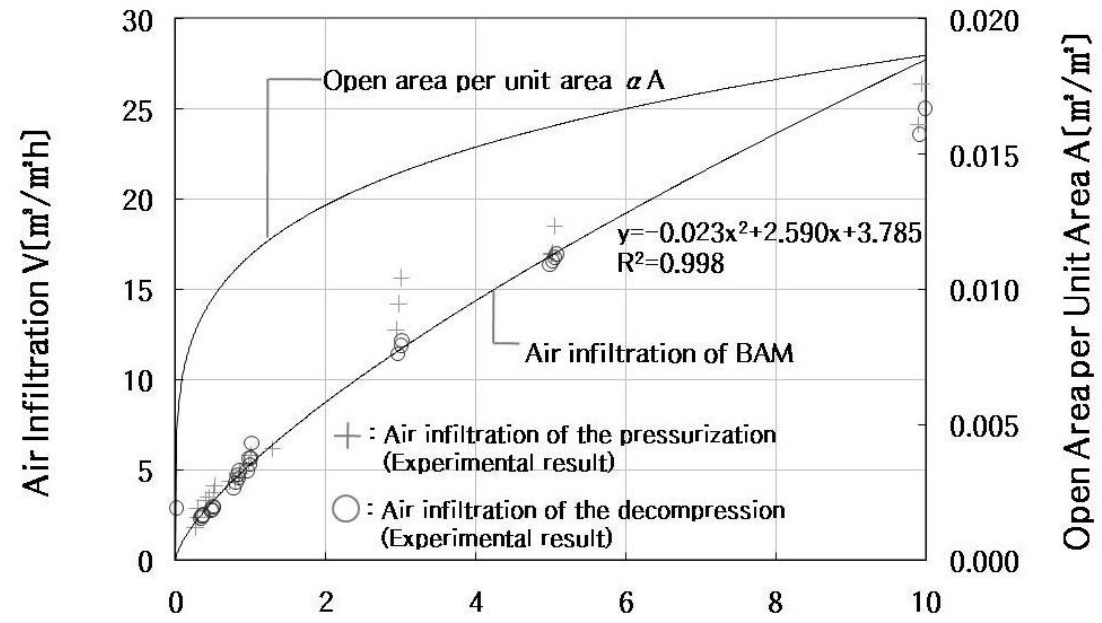

\section{Differential Pressure P [Pa]}

Figure 6. Infiltration and opening area per unit area of the BAM.

\subsubsection{Temperature Increase in Inflow Air}

Figure 7 shows the temperature variation of the outside air flowing into the room under constant air permeation. For air permeations within $3-46 \mathrm{~m}^{3} /\left(\mathrm{m}^{2} \mathrm{~h}\right)$ under the conditions set for outside air (temperature $=5^{\circ} \mathrm{C}$, which is the design condition of the member), the temperature of outside air flowing into the room varied between 8.1 and $18.1^{\circ} \mathrm{C}$. Although the experimental values indicated in Figure 7 differ somewhat from those of a previous study (Yoon and Hoyano [7]) due to the casing of the core part of the BAM in the present study, they remain largely comparable. The differences between the modeled and experimentally measured temperatures are within $0.5{ }^{\circ} \mathrm{C}$ and dependent on the amount of air infiltration. This could be due to subtle changes in the pressure and temperature conditions of the chamber. However, the differences between the measured and calculated values in the present study are within $5 \%$, which thus validates the proposed numerical models for predicting heat and air transfer.

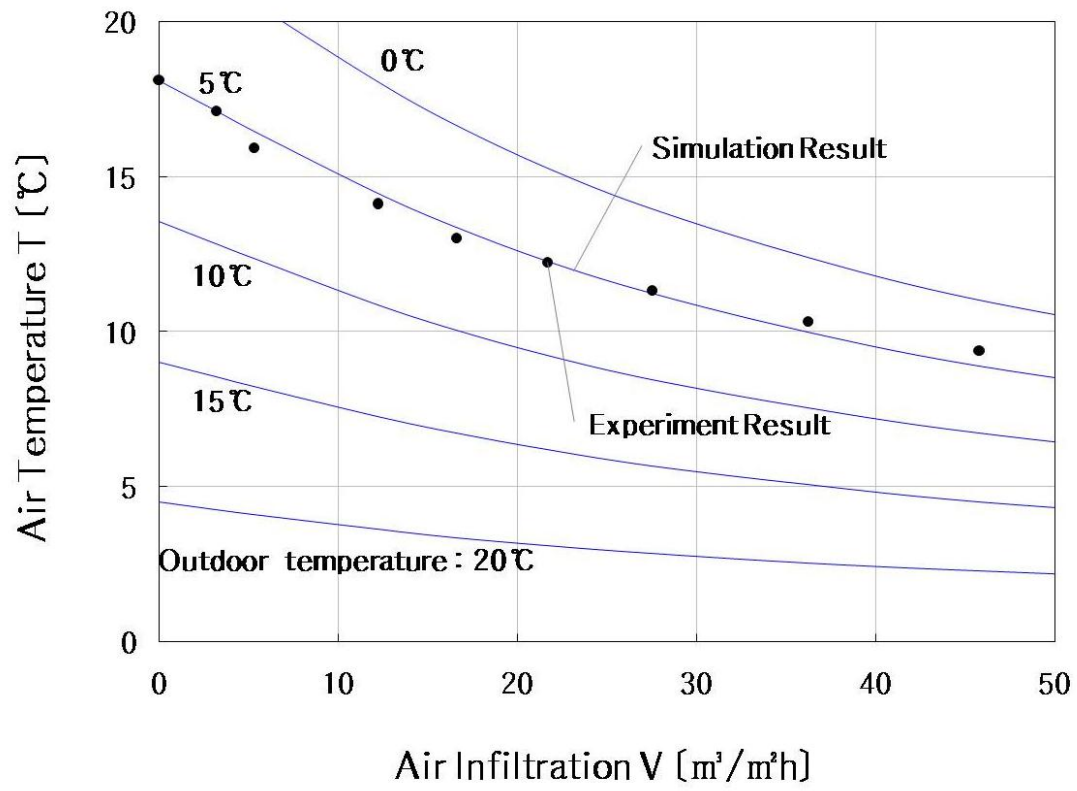

Figure 7. Effect of temperature increase on air infiltration. 


\subsubsection{Equivalent Heat Transfer Coefficient (U-value)}

The most universal indicator of the insulation performance of a member is the heat transfer coefficient. In the particular case of a BAM, as air passes through the member and heat flow occurs, the equivalent heat transfer coefficient can be used to assess insulation performance in the manner employed by Taylor and Imbabi [11,12] in their study of dynamic insulation. The formula for calculating the equivalent heat transfer coefficient (U-value) is as follows:

$$
U d=\frac{V \gamma C p}{R s(\exp (V \gamma C p)-1)}
$$

where:

Ud: Dynamic U-value for a multi-layer envelope $\left[\mathrm{W} /\left(\mathrm{m}^{2} \mathrm{~K}\right)\right]$

Rs: Thermal resistance of the wall $\left[\left(\mathrm{m}^{2} \mathrm{~K}\right) / \mathrm{W}\right]$

Figure 8 shows the calculated equivalent heat transfer coefficient. As can be observed, the coefficient varies significantly with varying low air infiltration rate, but tends to stabilize with increasing air infiltration rate. The emissivity of the aluminium sheets of the BAM sample was 0.135 , for which the equivalent heat transfer coefficient was determined to vary between 0.069 and $0.601 \mathrm{~W} /\left(\mathrm{m}^{2 \circ} \mathrm{C}\right)$ when the air infiltration rate varied between 1.3 and $17.0 \mathrm{~m}^{3} /\left(\mathrm{m}^{2} \mathrm{~h}\right)$. The emissivity of the aluminium sheets of the BAM was measured by a simplified emissivity test using an infrared radio meter (Dai Nippon Printing Co., Tokyo, Japan).

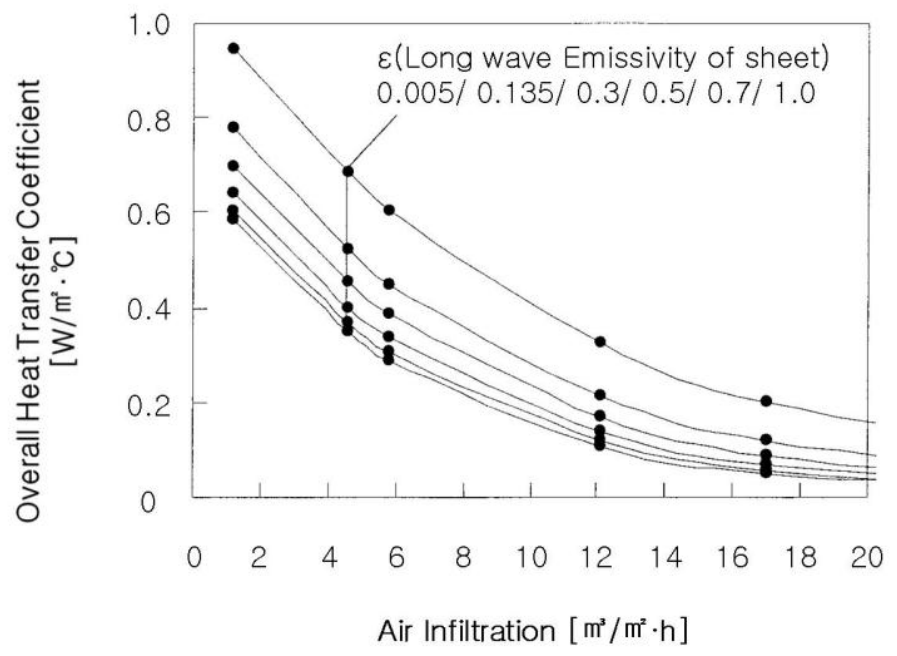

Figure 8. Overall heat transfer coefficient under long-wave emissivity.

\section{Performance Evaluation by Numerical Simulation}

\subsection{Overview of Numerical Simulation}

\subsubsection{Numerical Simulation Method}

To evaluate the thermal performance of a house in which a BAM is used, it is necessary to determine the air infiltration quantity, the air infiltration area, and the air infiltration direction in each part of the house in which the member is installed. The present study employed an algorithm for calculating the ventilation rate and heat transmission through the BAM by air inflow and outflow for each wall surface considered in the calculation (see Figure 9).

To predict the natural ventilation rate when using a BAM, the pressure judgment method or network method may be used [13]. The annual ventilation rates can also be calculated using air 
temperature, wind velocity, and wind direction with respect to time. Furthermore, heat flow through the BAMs under conditions of air infiltration with calculated using the numerical models for heat and air movements presented in the previous section.

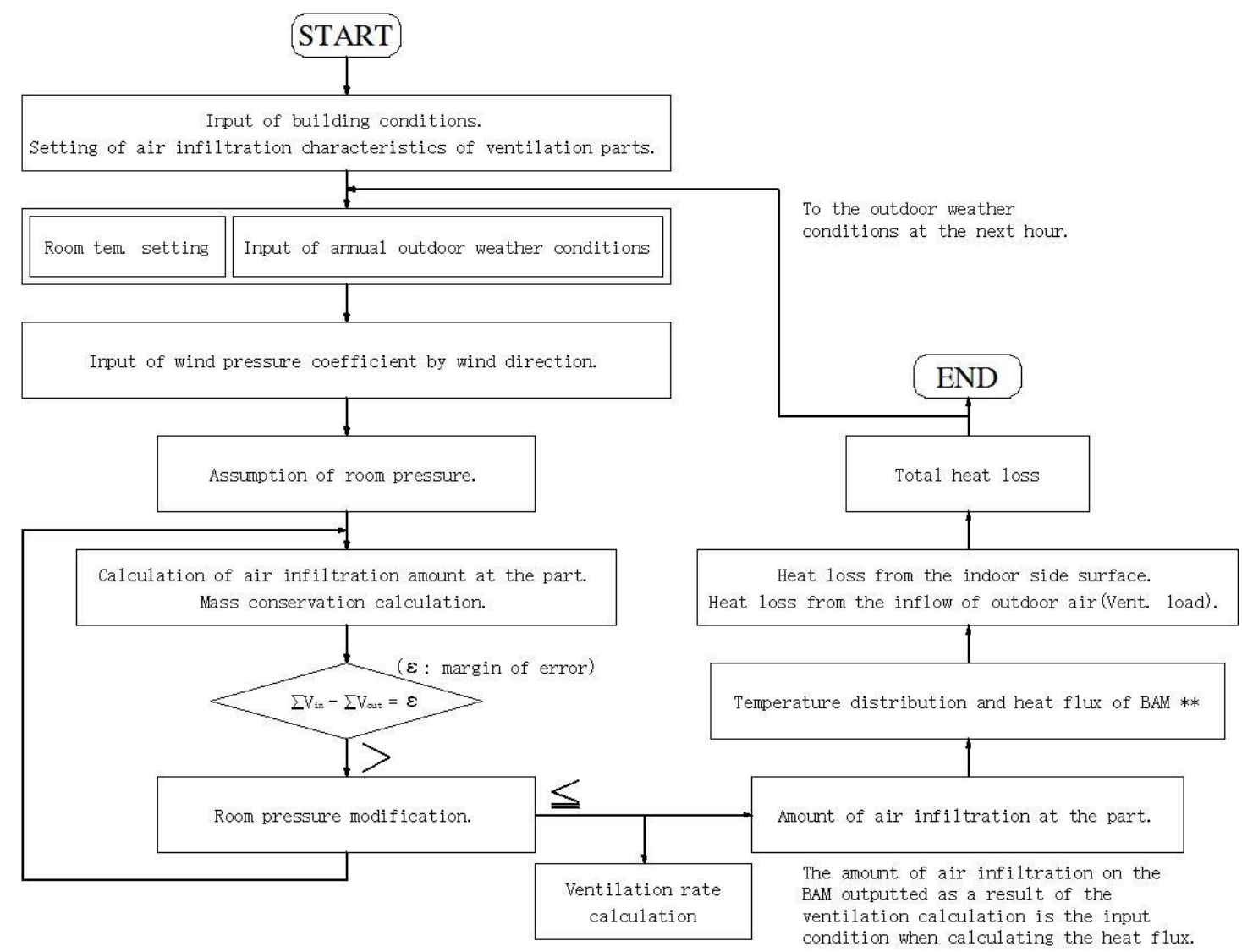

Figure 9. Combination of BAM design and ventilation rate prediction.

\subsubsection{Passive House Models}

Five different models of two-storey houses $(10.0 \times 10.0 \times 4.8 \mathrm{~m})$ are shown in Figure 10. Included are those of highly insulated and extremely airtight houses without BAMs, and houses using two types of BAMs (type 1: $\alpha A=10 \mathrm{~cm}^{2} / \mathrm{m}^{2}$, type 2: $\alpha A=20 \mathrm{~cm}^{2} / \mathrm{m}^{2}$ ) designed for use in a warm climate by insulating the ceiling and exterior walls. In the application of BAMs in a real two-storey house, it is necessary to consider installation in the ceiling of a room on the first floor and in the roof. In this study, however, the members were installed in a horizontal plane in the ceiling and in a vertical plane in the exterior walls. The single-room house models were set up as shown in Figure 10 to enable evaluation of results of simple changes in the ventilation and insulation performances.

BAM types 1 and 2 were specifically installed in the east and west exterior walls of the house and in the ceiling. When installing the ceiling members, they were mounted on the highest ceiling. The temperature in the attic was set to that of the outdoor air, based on the assumption that the attic was sufficiently ventilated. With the exception of the locations where the BAMs were installed, the other parts of the house models were assumed to have a heat transfer coefficient that produced an insulation performance of $0.53 \mathrm{~W} / \mathrm{m}^{2 \circ} \mathrm{C}$. In Seoul, which was the target area of the simulation, air pressure is more stable on the surfaces of eastern and western walls, which cooperate with the southern and northern sides. The BAMs were thus installed in the eastern and western exterior walls using fewer openings in the case.

The insulation performance of the exterior walls of Case 3, in which no BAM was installed, was set to $0.53 \mathrm{~W} /\left(\mathrm{m}^{2 \circ} \mathrm{C}\right)$, which is based on the heat transfer coefficient of the parts of the other 
houses where no BAM was installed. A ventilation rate of $0.7 \mathrm{ACH}$ was assumed to be achieved by mechanical ventilation.

\begin{tabular}{|c|c|c|c|c|}
\hline $\begin{array}{l}\text { Applicable } \\
\text { Parts }\end{array}$ & CASE & $\begin{array}{l}\text { BAM TYPE1 } \\
\alpha A: 10 \mathrm{~cm}^{2} / \mathrm{m}^{2} \\
\text { Coefficient of opening } \\
\text { characteristics } \mathrm{n}: 0.78\end{array}$ & CASE & $\begin{array}{l}\text { BAM TYPE2 } \\
\alpha A: 20 \mathrm{~cm}^{2} / \mathrm{m}^{2} \\
\text { Coefficient of opening } \\
\text { characteristics } \mathrm{n}: 0.78\end{array}$ \\
\hline $\begin{array}{l}\text { East exterior } \\
\text { wall \& } \\
\text { West exterior } \\
\text { wall } \\
\text { ( } 2 \text { sides })\end{array}$ & $1-1$ & & $1-2$ & \\
\hline $\begin{array}{l}\text { East exterior } \\
\text { wall \& } \\
\text { West exterior } \\
\text { wall \&Ceiling } \\
\text { ( } 3 \text { sides) }\end{array}$ & $2-1$ & & $2-2$ & \\
\hline $\begin{array}{l}\text { Not applicable } \\
\text { (high-insulated } \\
\text { and } \\
\text { air-tightened } \\
\text { assumed) }\end{array}$ & 3 & & ) Ventilat & $\begin{array}{l}\text { Ion method: mechanical. } \\
\text { coefficient heat transfer. } \\
\text { eiling : } 0.24\left[\mathrm{~W} / \mathrm{m}^{2} / \mathrm{K}\right] \\
\text { ixterior Wall }: 0.53\left[\mathrm{~W} / \mathrm{m}^{2} / \mathrm{K}\right] \\
\text { loor : } 0.34\left[\mathrm{~W} / \mathrm{m}^{2} / \mathrm{K}\right] \\
\text { ion: } 0.5 \mathrm{ACH} \text { or } 1.0 \mathrm{ACH} \text {. }\end{array}$ \\
\hline
\end{tabular}

Figure 10. House models used for the simulations.

\subsubsection{Outdoor Weather Conditions}

To calculate the ventilation and insulation performances in the Tokyo area, standard weather data on temperature, wind velocity, and wind direction from the Society of Heating, Air-conditioning and Sanitary Engineers of Japan (SHASE) were applied to the outdoor air. The same data were also used to calculate heat load. The data comprise a collection of well-organized standard annual values of temperature, humidity, solar radiation, atmospheric radiation, and wind velocity and direction. With regard to the wind pressure elements, the ventilation rates were predicted based on data for eight different wind directions.

\subsubsection{Indoor Conditions}

As the main purpose of the study was to determine changes in the ventilation rate and insulation performance with respect to conditions in the Tokyo area, the annual room temperature of the house models was set to a constant value of $25^{\circ} \mathrm{C}$. It would, however, be beneficial to develop a natural room temperature prediction algorithm that takes heat storage into consideration, and this will be undertaken in a future study.

\subsection{Simulation Results}

\subsubsection{Natural Ventilation Capacity}

The annual natural ventilation rates were calculated for scenarios with BAMs installed in the exterior walls and ceilings of houses in the Tokyo area. Themonthly results were organized according to ACH rates of $<0.5,0.5-2.0$, and $>2.0$ (see Figure 11). 


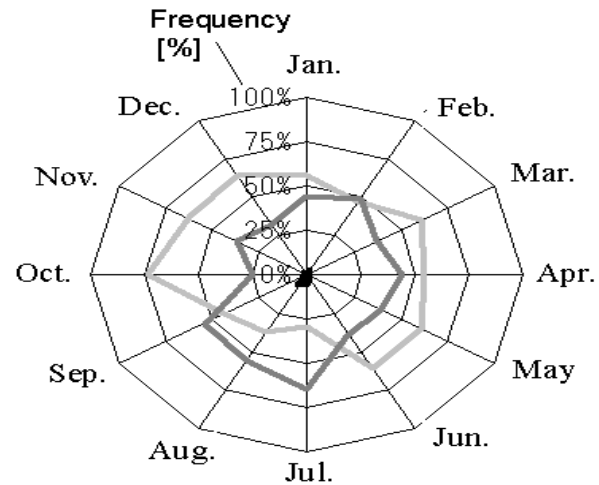

(a) CASE 1-1

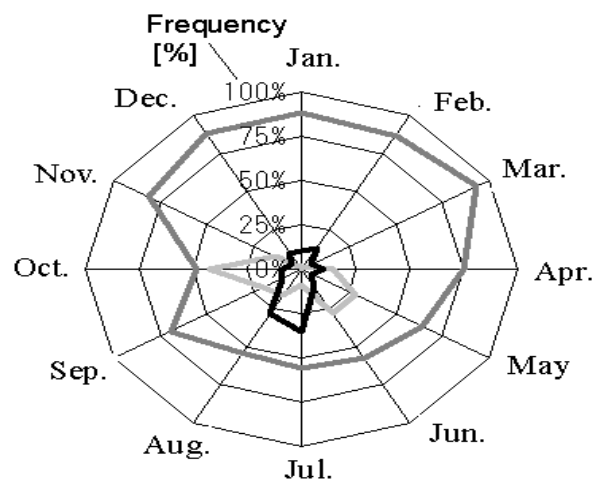

(d) CASE 1-2

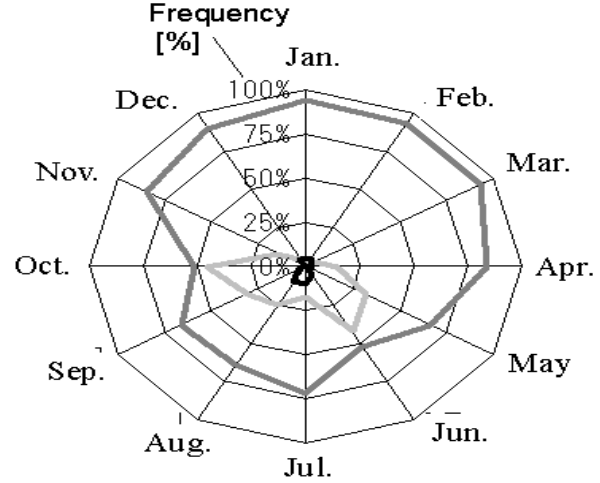

(b) CASE 2-1

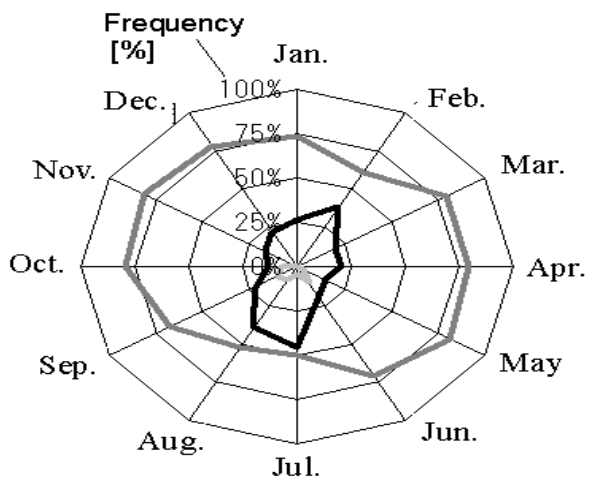

(e) CASE 2-2

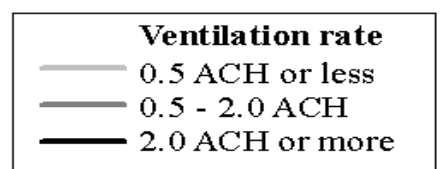

\begin{tabular}{|cl} 
Frequency \\
{$[\%]$}
\end{tabular}$=\frac{\begin{array}{l}\text { Number of hours } \\
\text { when ventilation rate was }\left[\begin{array}{l}0.5 \mathrm{ACH} \text { or less } \\
0.5-2.0 \mathrm{ACH} \\
2.0 \mathrm{ACH} \text { or more }\end{array}\right]\end{array}}{\text { Number of days in the month*24[hrs }]}$

Figure 11. Annual ventilation rate change in a passive house with BAMs.

The natural ventilation performance of the BAMs were verified by checking whether

- The required minimum ventilation rate of $0.5 \mathrm{ACH}$ was achieved;

- The annual required ventilation rate of $\geqslant 0.5 \mathrm{ACH}$ was maintained;

- Heat loss by increased air infiltration under strong winds was suppressed to the lowest possible level to ensure a stable ventilation rate.

Apart from Case 1-1, the required minimum ventilation rate of $\geqslant 0.5 \mathrm{ACH}$ was always achieved during the winter season (December-February). In Case 1-1, BAMs with $\alpha A=10 \mathrm{~cm}^{2} / \mathrm{m}^{2}$ were installed in only the eastern and western exterior walls. It was observed that ventilation rates of $<0.5 \mathrm{ACH}$ accounted for more than $50 \%$ of all the results. This reveals the difficulty of achieving the required minimum ventilation rate in winter. In Case 2-2, the required ventilation rate of $\geqslant 0.5 \mathrm{ACH}$ was consistently achieved. Case 2-1 had the most stable ventilation rate, which was achieved by installing members with $\alpha A=10 \mathrm{~cm}^{2} / \mathrm{m}^{2}$ in three surfaces, namely, the eastern and western exterior walls and the ceiling. This maintained the required ventilation rate of $\geqslant 0.5 \mathrm{ACH}$ throughout the winter season and an overall $5 \%-8 \%$ frequency of ventilation rate $\geqslant 2.0 \mathrm{ACH}$ during winter. It is thus possible to reduce heat losses due to increased ventilation associated with wind gusts. 


\subsubsection{Total Heat Loss (Indoor Heat Load)}

Figure 12 shows the calculated total heat loss between December and February (winter season) for Cases 1-2, 2-1, 2-2 and 3, in which BAMs were installed in two exterior walls using the most basic method.

In Case 3, which utilized mechanical ventilation, a ventilation rate of $1.0 \mathrm{ACH}$, (equivalent to the average ventilation rates of Cases 1-2 and 2-1), the performance was such that total heat loss in Cases 1-2, 2-1 and, 2-2 (with BAMs) was reduced by 15.3\%-40.2\%. This confirms, the energy saving effect of the BAM.

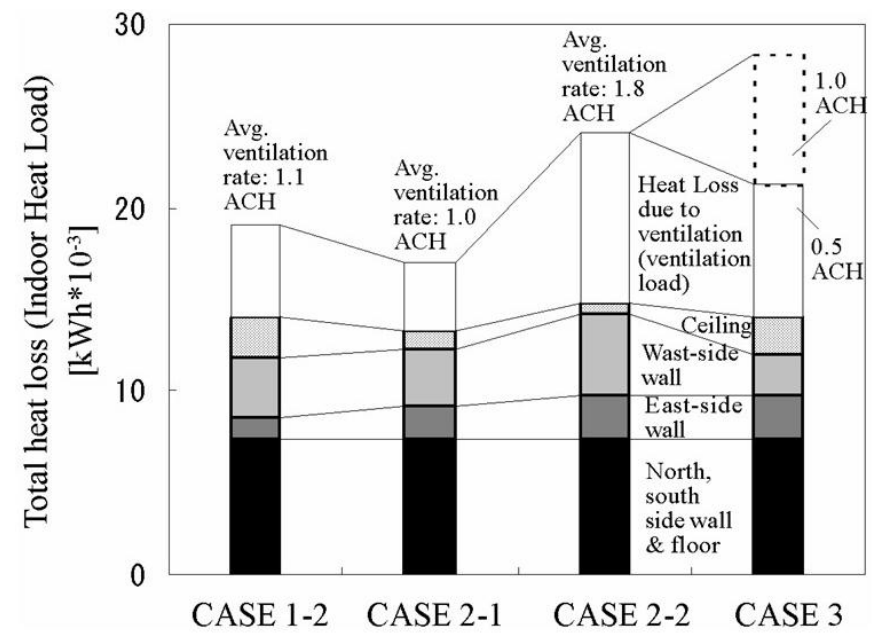

Figure 12. Total heat load between Dec. and Feb.

In Case 2-2, in which BAMs with $\alpha A=20 \mathrm{~cm}^{2} / \mathrm{m}^{2}$ were installed in two exterior walls and the ceiling, the required ventilation rate was achieved, including during an intermediate period when the difference between the indoor and outdoor temperatures was extremely small. However, heat loss in this case increased compared to Cases 1-2 and 2-1. To use BAMs to ensure the required ventilation rate for cases 1-2 and 2-1 during the noted intermediate period, further study is required to investigate how a stable ventilation rate can be achieved under varying wind pressure.

\section{Conclusions}

In this study, chamber experiments and numerical simulations of natural ventilation and heat loss, were performed to verify the performance of BAMs applied to houses in a warm-climate area. The numerical models used to predict the heat and air movements were also verified by comparing by comparison with a one-dimensional chamber experiment, which revealed a difference of within $5 \%$ in the temperature of the air flowing into the room from outside. Case studies were conducted using BAMs with two different specifications, installed in the ceilings and exterior walls of model houses in the Tokyo area. This was done to confirm the annual ventilation performance and energy-saving effects of the members. In the cases of BAMs with $\alpha A=20 \mathrm{~cm}^{2} / \mathrm{m}^{2}$ installed in two exterior walls and the ceilings, the annual required ventilation rate of $\geqslant 0.5 \mathrm{ACH}$ was consistently achieved. In addition, heat loss was reduced by $15.3 \%-40.2 \%$ depending on the BAM installation position and the area difference compared to a house with general insulation and mechanical ventilation.

Acknowledgments: This research was supported by Basic Science Research Program through the National Research Foundation of Korea (NRF) funded by the Ministry of Education (NRF-2012R1A1A4A01015404).

Author Contributions: All authors participated in the research, analysis and interpretation of the data, as well as the design and production of this article. All authors agree to be listed and approve the submitted and accepted versions of the publication.

Conflicts of Interest: The authors declare no conflict of interest. 


\section{Nomenclature}

$\begin{array}{ll}V & \text { Volume of air infiltration, } \mathrm{m}^{3} /\left(\mathrm{m}^{2} \mathrm{~s}\right) \\ \mathrm{C} & \text { Flow coefficient } \\ A & \text { Opening area per unit area, } \mathrm{m}^{2} / \mathrm{m}^{2} \\ \gamma & \text { Air density, } \mathrm{kg} / \mathrm{m}^{3} \\ P & \text { Air pressure, Pa } \\ \mathrm{Nu} & \text { Nusselt number } \\ h_{c} & \text { Convective heat transfer rate, } \mathrm{W} /\left(\mathrm{m}^{2 \circ} \mathrm{C}\right) \\ \lambda & \text { Thermal conductivity of air, } \mathrm{W} /(\mathrm{mK}) \\ d & \text { Equivalent diameter of pipe section, } \mathrm{m} \\ D & \text { Thickness of air layer, } \mathrm{m} \\ h_{r} & \text { Radiant heat transfer rate, } \mathrm{W} /\left(\mathrm{m}^{2 \circ}{ }^{\circ} \mathrm{C}\right) \\ \varepsilon_{n} & \text { Emissivity of aluminium sheet } \\ T_{n} & \text { Surface temperature of aluminium sheet } n,{ }^{\circ} \mathrm{C} \\ \sigma & \text { Stefan-Boltzmann constant, } \mathrm{W} /\left(\mathrm{m}^{2} \mathrm{~K}\right) \\ C p & \text { Specific heat at constant pressure, } \mathrm{J} /\left(\mathrm{kg}{ }^{\circ} \mathrm{C}\right) \\ T_{k} & \text { Temperature of air layer } \mathrm{k},{ }^{\circ} \mathrm{C} \\ E_{c} & \text { Convective heat transfer, } \mathrm{W} / \mathrm{m}^{2} \\ E_{r} & \text { Radiant heat transfer, } \mathrm{W} / \mathrm{m}^{2} \\ E_{i} & \text { Heat movement accompanying air infiltration, } \mathrm{W} / \mathrm{m}^{2} \\ U d & \text { Dynamic } \mathrm{U}-\text { value for a multi-layer envelope, } \mathrm{W} /\left(\mathrm{m}^{2} \mathrm{~K}\right) \\ R s & \text { Thermal resistance of the wall, }\left(\mathrm{m}^{2} \mathrm{~K}\right) / \mathrm{W} \\ m & \text { Number of aluminium films } \\ r & \text { Indoor } \\ o & \text { Outdoor }\end{array}$

\section{References}

1. Hoyano, A.; Sugawara, M.; Sato, E. Proposal of a Breathing Wall as an Architectural Member for a Passive Solar System in a Temperate and Humid Climate Region. In Proceedings of the Pan Pacific Symposium on Building and Urban Environment Conditioning in Asia, Nagoya, Japan, 16-18 March 1995; Volume 1, pp. 43-52.

2. Dimoudi, A.; Androutsopoulos, A.; Lykoudis, A. Experimental work on a linked, dynamic and ventilated, wall component. Energ. Build. 2004, 36, 443-453. [CrossRef]

3. Imbabi, M.S. Modular breathing panels for energy efficient, healthy building construction. Renew. Energ. 2006, 31, 729-738. [CrossRef]

4. Stavridou, A.D. Breathing architecture: Conceptual architectural design based on the investigation into the natural ventilation of buildings. Front. Architect. Res. 2015, 4, 127-145. [CrossRef]

5. Biserni, C.; Garai, M. First and second law analysis applied to building envelope: A theoretical approach on the potentiality of Bejan's theory. Energ. Rep. 2015, 1, 181-183. [CrossRef]

6. Sugawara, M.; Hoyano, A.; Sato, E.; Sakuma, H. Proposal of an architectural member with multi-airlayered body constructed of aluminum sheets having fine holes and study on a calculation method of air, heat, and moisture transfer, development of a breathing wall part 2. J. Archit. Plann. Environ. Eng. 1997, 499, 43-48.

7. Yoon, S.; Hoyano, A. Passive ventilation system that incorporates a pitched roof constructed of breathing walls for use in a passive solar house. Sol. Energy 1998, 64, 189-195. [CrossRef]

8. Ower, E.; Pankhurst, R.C. The Measurement of Air Flow; Pergamon Press: Oxford, UK, 1977.

9. Holman, J.P. Heat Transfer, 7th ed.; McGraw-Hill: New York, NY, USA, 1992.

10. American Society of Heating, Refrigerating and Air-Conditioning Engineers. Ventilation and Thermal Loads. In ASHRAE Handbook -Fundamentals; ASHRAE: Atlanta, GA, USA, 1993.

11. Taylor, B.J.; Cawthorne, T.D.A.; Imbabi, M.S. Analytical investigation of the steady state behavior of dynamic and diffusive building envelopes. Build. Environ. 1996, 31, 519-525. [CrossRef] 
12. Taylor, B.J.; Imbabi, M.S. The application of dynamic insulation in buildings. Renew. Energ. 1998, 15, 377-382. [CrossRef]

13. Yoshino, H.; Nagatomo, M.; Matsumoto, H.; Utsumi, Y.; Yamamoto, Y. Verication of calculation method of air infiltration for a detached wooden houses: In case of a single-room model. J. Archit. Plann. Environ. Eng. 1990, 412, 19-29. 